\title{
Sensorless Control for Joint Drive Unit of Lower Extremity Exoskeleton with Cascade Feedback Observer
}

\author{
Pei Pei $\mathbb{D}^{1},{ }^{1}$ Zhongcai Pei, ${ }^{1}$ Zhengqiang Shi, ${ }^{2}$ Zhiyong Tang $\mathbb{D},{ }^{1}$ and Yang Li ${ }^{1}$ \\ ${ }^{1}$ School of Automation Science and Electrical Engineering, Beihang University, Beijing 100191, China \\ ${ }^{2}$ Beijing Institute of Precise Mechatronic Controls, Beijng 100076, China \\ Correspondence should be addressed to Zhiyong Tang; zyt_76@buaa.edu.cn
}

Received 13 July 2018; Revised 2 October 2018; Accepted 18 October 2018; Published 30 October 2018

Academic Editor: Luis J. Yebra

Copyright (C) 2018 Pei Pei et al. This is an open access article distributed under the Creative Commons Attribution License, which permits unrestricted use, distribution, and reproduction in any medium, provided the original work is properly cited.

In this paper, a sensorless control method for joint drive unit driven by BLDC motor of low extremity exoskeleton, cascade feedback observer identification method, is proposed. The cascade feedback observer identification method is based on improved Integral-Switching-Function Sliding-Mode-Observer (ISF-SMO) and adaptive FIR filter. The improved Integral-SwitchingFunction Sliding-Mode-Observer is used to identify the back-EMF of motor. The sliding mode surface redesigned according to Integral-Switching-Function (ISF) eliminates the inevitable chattering problem in conventional Sliding-Mode-Observer (SMO). The stability condition of Integral-Switching-Function Sliding-Mode-Observer is obtained with Lyapunov function. Meanwhile, considering the estimation error and system instability caused by the mismatch between the actual resistance value $\left(R_{\mathrm{s}}\right)$ and the set resistance value, the LMS algorithm is used to estimate the resistance value online according to the structure of adaptive FIR filter. When system is running, the modified Integral-Switching-Function Sliding-Mode-Observer and adaptive FIR filter are used to modify the back-EMF and the resistance value by cascading feedback relation, and the modified back-EMF value is taken as the final output of the system. Because of considering the uncertainty of resistance caused by temperature variation, the robustness and stability of the cascade feedback observer can be improved. Meanwhile, higher estimation accuracy is obtained, and operation range of sensorless control is extended, which is suitable for motor in low speed region. Finally, the correctness and validity of the proposed method are verified by simulations and experiments.

\section{Introduction}

Brushless DC (BLDC) motor not only has the advantages of simple operation and reliable maintenance [1], but also has the advantages of simple control, high efficiency, and good performance of speed regulation as DC motor; therefore, it is widely used in aerospace, instrumentation, medical devices, robotics, and other fields. There are many examples of the use of BLDC motor as a power source in extremity exoskeleton systems, and some of them have achieved very successful results, such as HAL-5 [2], Lokomat [3], and Rewalk [4]. The correct commutation of BLDC motor based on rotor position information is needed in motor operation process, but the existence of position sensor has brought a series of disadvantages of BLDC motor application. The principle of highly integrated and high reliability should be followed in the design of extremity exoskeleton system; therefore, a sensorless BLDC motor is selected in the design of the joint drive unit (Figure 1), which will be controlled by sensorless control technology.

At present, sensorless control methods for BLDC motor can be divided into two categories: one is based on machine anisotropy $[5,6]$ and the other is based on mathematical model of BLDC motor [7, 8]. Anisotropy-based methods acquire rotor position by injecting high frequency (HF) signals into motor, which is suitable for sensorless control of ultralow speed operation. However, the injection of $\mathrm{HF}$ signals will bring additional loss and greater torque ripple. Mathematical model based methods are used to calculate rotor position according to the position information contained in motor mathematical model, which is suitable for the sensorless control of the middle and high speed operation. Mathematical model based methods include model reference adaptive system (MRAS) method [9], sliding mode observer 


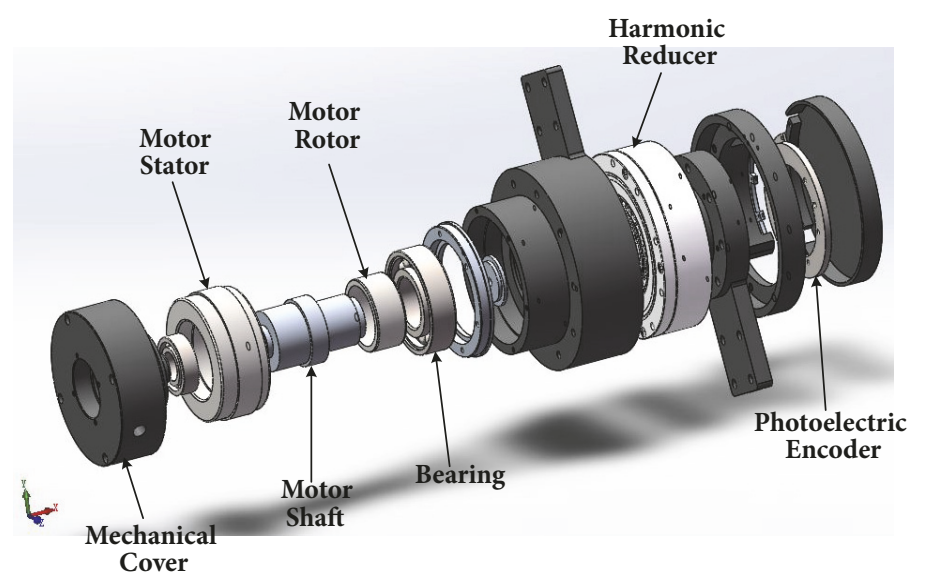

FIgURe 1: Joint drive unit.

(SMO) method [10, 11], Kalman filter method [12], and Luenburger observer [13]. Most of these methods obtain rotor position information by identifying back-EMF and usually use the zero-crossing of the nonconducted phase's back-EMF as the basis of motor commutation. The real commutation of motor is zero-crossing of phase's back-EMF adding a certain shift angle which is related to motor's speed directly, so the ideal commutation point cannot be obtained when a large fluctuation is in speed. This paper takes zero-crossings of the nonconducted line's back-EMF as the basis of motor commutation, which is corresponding to the commutation of Hall signal completely.

SMO methods are widely used in sensorless control of motor due to its simple structure and strong robustness to parameter variation. The first-order SMO as a kind of SMO is the most classical method to identify motor's backEMF. However, there is chatting problem in the first-order SMO, which requires a low filter to filter the output single of observer, so there is phase lag of identification result. In [14], a mathematical method is used to compensate phase lag. In [15], a hyperbolic tangent function is used instead of symbolic function in SMO, which avoids phase lag brought by low pass filter. In view of the disadvantage of the first-order SMO, the second-order SMO and the improved observer based on the second-order SMO are used to identify motor's back-EMF. The second-order SMO is improved in [16]. In [17], considering the nonlinear effect of power inverter, an adaptive second-order SMO is designed, which reduces observation error effectively. A global fast terminal SMO based on linear SMO and fast terminal SMO is proposed in [18], which made full use of the advantages of linear SMO and fast terminal SMO.

The parameter $R_{s}$ is contained in most of the identification results, which is not a constant in the process of motor operation due to the reasons of temperature rise and so on. So the estimation of the resistance value online plays an important role in sensorless control, especially in low speed region, where motor's back-EMF is relatively small compared to voltage drop. Mismatch between actual and set value of the resistance value may lead to rotor position and speed estimation error and even system instability. The parameters identification of motor has been studied by many researchers. An online identification technique of the parameters which were needed to minimize power consumption in an application with PMSM was proposed in [19]. Two new parameters estimation methods for a single-phase induction machine (SPIM) were proposed in [20]. Besides, some researchers have combined the parameters identification of motor with no sensor control of sensor. In [21], a model reference adaptive algorithm based on adaptive fuzzy neural network was proposed, which could identify back-EMF very well in the case of motor parameter perturbations, but the control law designed by this method was too complex. Reference [8] proposed a two-stage high gain observer which could overcome the effect of parameter perturbation on system identification. In [22], an identification method which combined second-order sliding mode super-twisting algorithm (STA) and model reference adaptive system (MRAS) was proposed. By identifying the resistance value online, the influence of the uncertainty of resistance value on the system can be overcome and the speed working range of sensorless control was extended. In [23], the method of neural network was used to identify the resistance value according to the rotor position deviation, but the identification effect was greatly reduced under dynamic condition. A parallel estimation method of a super-twisting algorithm and second-order SMO is proposed in [24], which had overcome the influence of the uncertainty of resistance value and had achieved good results in low speed region.

Aiming at sensorless control of joint drive unit driven by BLDC motor of lower extremity exoskeleton system, a cascade feedback observer identification method based on improved ISF-SMO and adaptive FIR filter is proposed in this paper. Firstly, a novel ISF-SMO based on the improved ISF sliding mode control is designed, which can eliminate the chatting problem of the first-order SMO without low pass filter. The stability condition of ISF-SMO is obtained with Lyapunov function. In addition, LMS algorithm according to the structure model of adaptive FIR filter is used to identify the resistance value $\left(R_{s}\right)$ online instead of using 


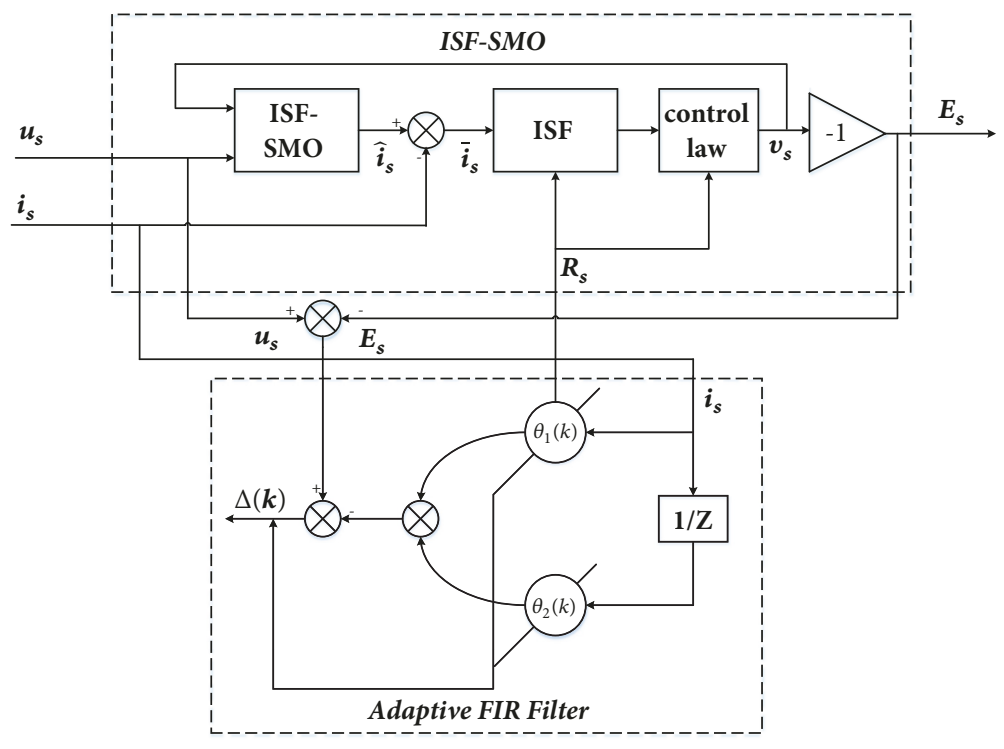

FIGURE 2: Schematic diagram of cascade feedback observer.

fixed value. Then, the robustness and identification accuracy of the system are improved. Furthermore, ISF-SMO and adaptive FIR filter constitute a cascade feedback observer identification system for sensorless control of BLDC motor. Finally, the correctness and effectiveness of the proposed cascade feedback observer identification method is verified by simulations and experiments.

\section{Design of Cascade Feedback Observer}

The cascade feedback observer system proposed in this paper includes two subsystems: ISF-SMO and adaptive FIR filter. When system is running, the two subsystems belong not only to parallel relationship, but to cascade feedback relationship as well. The schematic diagram of cascade feedback observer is shown in Figure 2. The input of cascade feedback observer is voltage and current, and the output is the estimated value of back-EMF. First of all, the ISF-SMO will identify line backEMF based on the input line voltage and line current of the previous period. The line back-EMF is used as the input of the adaptive FIR filter identification system, and then the adaptive FIR filter identifies the equivalent value of resistance according to the line voltage, line current, and line back-EMF. The equivalent value of resistance is fed back to ISF-SMO identification system as the input. The ISF-SMO identifies the line back-EMF as the final output according to the values of line voltage, line current, and resistance. At the same time it is fed back to adaptive FIR filter identification system as the input. The two subsystems will be introduced in Sections 2.1 and 2.2 , respectively.

2.1. Integral-Switch-Function Sliding-Mode-Observer (ISF$S M O)$ Identification System. Neglecting the influence of iron losses, eddy-current losses, and saturation effect, the mathematical model of Brushless DC motor can be described as

$$
\begin{aligned}
u_{a} & =R_{s} i_{a}+L_{s} \frac{d i_{a}}{d t}+e_{a}+u_{0} \\
u_{b} & =R_{s} i_{b}+L_{s} \frac{d i_{b}}{d t}+e_{b}+u_{0} \\
u_{c} & =R_{s} i_{c}+L_{s} \frac{d i_{c}}{d t}+e_{c}+u_{0}, \\
i_{a}+i_{b}+i_{c} & =0,
\end{aligned}
$$

where $u_{a}, u_{b}$, and $u_{c}$ are phase's voltage of stator, $i_{a}, i_{b}$, and $i_{c}$ are phase's current of stator, $e_{a}, e_{b}$, and $e_{c}$ are phase's backEMF of stator, $R_{s}$ is resistance of stator, and $L_{s}$ is equivalent inductance.

There is a certain phase shift angle between the zerocrossings of phase's back-EMF and the commutation point of Hall. However, the zero-crossings of line's back-EMF and the commutation point of the Hall signal are completely corresponding. Equations (1) and (2) can be translated into expressions of line voltage and line current as

$$
\begin{aligned}
u_{a b} & =R_{s} i_{a b}+L_{s} \frac{d i_{a b}}{d t}+e_{a b} \\
u_{b c} & =R_{s} i_{b c}+L_{s} \frac{d i_{b c}}{d t}+e_{b c} \\
u_{c a} & =R_{s} i_{c a}+L_{s} \frac{d i_{c a}}{d t}+e_{c a}, \\
i_{a b}+i_{b c}+i_{c a} & =0,
\end{aligned}
$$

where $u_{a b}, u_{b c}$, and $u_{c a}$ are line's voltage of stator, and $i_{a b}, i_{b c}$, and $i_{c a}$ are line's current of stator.

The mathematical model of BLDC motor is simplified into two linear independent first-order current models in parallel. The space state equation can be expressed as follows:

$$
\dot{X}=A X+B(U-E)
$$




$$
\mathrm{Y}=\mathrm{CX}
$$

where $X=\left[x_{1}, x_{2}\right]^{T}=\left[i_{a b}, i_{b c}\right]^{T}, U=\left[u_{1}, u_{2}\right]^{T}=\left[u_{a b}, u_{b c}\right]^{T}$ and $E=\left[e_{a b}, e_{b c}\right]^{T}$,

$$
\begin{aligned}
& A=\left[\begin{array}{cc}
-\frac{R_{s}}{L_{s}} & 0 \\
0 & -\frac{R_{s}}{L_{s}}
\end{array}\right], \\
& B=\left[\begin{array}{cc}
-\frac{1}{L_{s}} & 0 \\
0 & -\frac{1}{L_{s}}
\end{array}\right], \\
& C=[1,1]^{T} .
\end{aligned}
$$

According to the state space equation of motor, an Integral-Switching-Function Sliding-Mode-Observer is designed as

$$
\dot{\hat{X}}=A \widehat{X}+B(U+V)
$$

where $\widehat{X}=\left[\widehat{\imath}_{a b}, \widehat{\imath}_{b c}\right]^{T}$ is the estimate of $\mathrm{X} ; \mathrm{V}=\left[v_{a b}, v_{b c}\right]^{T}$ is the control law of SMO.

By subtracting (5) from (8), we can get state equation of state variable error as

$$
\dot{\bar{X}}=A \bar{X}+B(V+E),
$$

where $\bar{X}=\widehat{X}-X$.

The sliding mode surface of an Integral-SwitchingFunction Sliding-Mode-Observer is designed as

$$
\mathrm{S}=\mathrm{C}\left(\bar{X}-B K \int \bar{X} d t\right)
$$

where $C$ is positive constant coefficient matrix; $K$ is state feedback gain matrix.

When the system state is on the sliding mode surface, $S=$ $\dot{S}=0$, that is,

$$
\dot{\bar{X}}=B K \bar{X}
$$

In this case, an ideal control effect can be obtained by adjusting $K$ appropriately.

In order to identify the line's back-EMF of motor, the control law of the Integral-Switching-Function Sliding-ModeObserver is needed. In this paper, the control law $(V)$ of ISFSMO consists of two parts: equivalent control quantity $\left(V_{e q}\right)$ and switching control quantity $\left(V_{n}\right)$. Taking a line's current $\left(i_{a b}\right)$ as an example, the other two are similar. The control law $(v)$ of the ISF-SMO is designed as

$$
\begin{aligned}
V & =V_{e q}+V_{n} \\
V_{e q} & =R_{S} * \bar{\imath}_{s} \\
V_{n} & =\frac{1}{B}\left(\dot{\overrightarrow{i_{s}}}-A \widehat{\imath_{s}}\right)-K \overline{i_{s}}+f \operatorname{sgn}(S),
\end{aligned}
$$

where, $f \geq|E|$; $K$ is negative real number; $S$ is sliding mode surface of ISF-SMO.
When the system moves on the sliding surface, $\overline{\overline{i_{s}}}=\dot{\overline{i_{s}}}=0$, then from (9) we obtain

$$
E=-V \text {. }
$$

According to (12), the identification result contains differential component $\dot{\hat{\imath}}_{s}$. In practical application, differentiator usually uses first-order differential signal, which is easy to introduce noise interference and then affect the identification accuracy. In this paper, a differential estimator is designed by using the second-order sliding mode algorithm to estimate the differential component $\left(\dot{\overrightarrow{v_{s}}}\right)$ in the identification result.

Define: $\widehat{s}_{s}=e(t)$ and $d \widehat{\imath}_{s} / d t=v_{0}(t)$, then we can get

$$
\begin{aligned}
\bar{e}(t) & =\widehat{e}(t)-e(t) \\
\dot{\bar{e}}(t) & =\dot{\hat{e}}(t)-v_{0}(t),
\end{aligned}
$$

where $\widehat{e}(t)$ is the estimator of $e(t)$ and $\bar{e}(t)$ is the estimating error.

The designed differential estimator is

$$
\begin{aligned}
\dot{\hat{e}}(t) & =v_{0}(t) \\
v_{0}(t) & =-\lambda_{0} *|\widehat{e}(t)-e(t)|^{1 / 2} * \operatorname{sgn}[\widehat{e}(t)-e(t)]+z \\
\dot{z} & =-\lambda_{1} * \operatorname{sgn}[\widehat{e}(t)-e(t)] .
\end{aligned}
$$

The convergence condition $[25,26]$ of differential estimator (15) is

$$
\begin{aligned}
\ddot{e}(t) & <a \\
\lambda_{1} & >a \\
\lambda_{0}{ }^{2} & \geq \frac{4 a\left(\lambda_{1}+a\right)}{\left(\lambda_{1}-a\right)},
\end{aligned}
$$

where $a$ is a positive constant. The controlled dynamics are affected by the choice of parameters $\lambda_{0}$ and $\lambda_{1}$. The parameter tuning methods of $\lambda_{0}$ and $\lambda_{1}$ are similar to ZieglerNichols method used in PID parameter tuning. Meanwhile, the parameter tuning methods are based on the gain setting method of high order sliding mode control.

When the differential estimator converges, we can obtain

$$
\dot{\hat{\imath}_{s}}=\frac{d \widehat{\imath}_{s}}{d t}=v_{0}(t) \text {. }
$$

The principle diagram of ISF-SMO is shown in Figure 2.

Then the stability of the improved ISF-SMO is analyzed with Lyapunov function.

Construct Lyapunov function as

$$
\mathrm{V}=\frac{1}{2} S^{T} S,
$$

where $S$ is the sliding mode surface of the ISF-SMO constructed by formula (10).

The differential of $V$ is

$$
\begin{aligned}
& \dot{V}=S^{T} \dot{S}, \\
& \dot{S}=C \dot{\bar{X}}-C B K \bar{X},
\end{aligned}
$$

where $\bar{X}=\widehat{X}-X ; \dot{\bar{X}}=\dot{\bar{X}}-\dot{X}$. Then (20) can be arranged as

$$
\dot{S}=C(\dot{\hat{X}}-\dot{X})-C B K \bar{X}
$$


By substituting (5) with (21), we can get

$$
\dot{S}=C \dot{\hat{X}}-C(A X+B U-B E)-C B K \bar{X} .
$$

By substituting (12) with (22), we can get

$$
\begin{aligned}
\dot{S}= & C \dot{\vec{X}}-C\{A X \\
& +B\left[\frac{1}{B}(\dot{\hat{X}}-A \widehat{X})-K \bar{X}+f \operatorname{sgn}(S)+\frac{A}{B} \bar{X}\right] \\
& -B E\}-C B K \bar{X} \\
= & C \dot{\widehat{X}}-C[A X \\
& +(\dot{\hat{X}}-A \widehat{X}-B K \bar{X}+B f \operatorname{sgn}(S)+A \bar{X})-B E] \\
& -C B K \bar{X} \\
= & C(-B f \operatorname{sgn}(S)+B E) .
\end{aligned}
$$

The derivation of the constructed Lyapunov function can be obtained by substituting (23) with (19):

$$
\dot{V}=C B(-s f \operatorname{sgn}(S)+s E) \text {. }
$$

With the conditions for constructing ISF-SMO: $f \geq|E|$, we can obtain

$$
\dot{V}=C B(-s f \operatorname{sgn}(S)+s E)=C B(-f|s|+s E) \leq 0 .
$$

Obviously, the reasonable selection of $f$ can ensure that the control law of ISF-SMO satisfies the sliding mode arrival condition, and the stability of the SMO can be guaranteed.

It can be seen from (12) that the identification result of line's back-EMF contains parameter $\left(R_{s}\right)$, and its exact value will be identified online.

2.2. Adaptive FIR Filter Identification System. Equation (3) can be rewritten as

$$
\begin{array}{r}
u_{m}=R i_{m}+L \frac{d i_{m}}{d t}+e_{m} \\
u_{m}-e_{m}=R_{m} i_{m}+L_{m} \frac{d i_{m}}{d t} .
\end{array}
$$

The upper expression can be regarded as FIR filter with input $\left(i_{m}\right)$ and output $\left(u_{m}-e_{m}\right)$. After discretization we can get

$$
u_{m}(k)-e_{m}(k)=\left(R+\frac{L}{\tau}\right) i_{m}(k)-\frac{L}{\tau} * i_{m}(k-1) .
$$

Define

$$
\begin{aligned}
& \mathrm{y}(\mathrm{k})=u_{m}(k)-e_{m}(k) \\
& \theta(k)=\left[R(k)-\frac{L(k)}{\tau},-\frac{L(k)}{\tau}\right]^{T} \\
& x(k)=\left[i_{m}(k), i_{m}(k-1)\right]^{T},
\end{aligned}
$$

the output term $\left(u_{m}(k)-e_{m}(k)\right)$ from (19) can be estimated by FIR filter. Define $\widehat{y}(k)$ as estimated output of filter, we can get

$$
\widehat{y}(k)=\theta^{T}(k) x(k) .
$$

The estimated deviation can be expressed as

$$
e(k)=y(k)-\hat{y}(k)=u_{m}(k)-e_{m}(k)-\hat{y}(k) .
$$

In the detection, if $e(k)$ converge to 0 , then $\widehat{y}(k)$ converge to $y(k)$ which also means that several parameter values in the vector $\theta(k)$ converge to the real parameters of system. The voltage and current values measured during the operation of system contain noise and the vector $\theta(k)$ is timevarying. Adaptive filter is used to identify the parameters of three-phase winding in real time and online. The schematic diagram of adaptive FIR filter is shown in Figure 4.

In practice, variance is usually used as criterion and objective function. The mean square error of $e(k)$ is

$$
\begin{aligned}
F(e(k)) & =E\left(e^{2}(k)\right) \\
& =E\left[y^{2}(k)-2 y(k) \hat{y}(k)-\widehat{y}^{2}(k)\right] .
\end{aligned}
$$

By substituting (30) with (32), then we can get

$$
\begin{aligned}
& F(e(k))=E\left[y^{2}(k)-2 y(k) \theta^{T}(k) x(k)\right. \\
& \left.\quad-\theta^{T}(k) x(k) x^{T}(k) \theta(k)\right]=E\left[y^{2}(k)\right] \\
& \quad-2 E\left[y(k) \theta^{T}(k) x(k)\right] \\
& \quad+E\left[\theta^{T}(k) x(k) x^{T}(k) \theta(k)\right] .
\end{aligned}
$$

Take $\theta^{T}(k)$ as parameter vector, then (33) can be expressed as

$$
\begin{aligned}
F(e(k))= & E\left[y^{2}(k)\right]-2 \theta^{T}(k) E[y(k) x(k)] \\
& +\theta^{T}(k) E\left[x(k) x^{T}(k)\right] \theta(k) \\
= & E\left[y^{2}(k)\right]-2 \theta^{T}(k) * P+\theta^{T}(k) * R \\
& * \theta(k),
\end{aligned}
$$

where $P=E[y(k) x(k)]$ is the output signal vector associated with the input signal; $R=E\left[x(k) x^{T}(k)\right]$ is the auto-correlation vector of the input signal. It can be deduced that the minimum value of (34) is obtained when its gradient to $\theta(k)$ is 0 , that is,

$$
g_{\theta}=\frac{\partial F}{\partial \theta}=-2 P+2 R \theta_{0}=0
$$

Then,

$$
\theta_{0}=R^{-1} P
$$

Equation (36) is the Wiener-Hopf equation [27]. If the solution of Wiener-Hoff equation exists, the parameter vector of the FIR filter can be found. The gradient descent method (the steepest descent method) is used to approximate the optimal solution vector. The gradient descent method takes the negative gradient direction as the search direction. The step size is smaller and the progress is slower with the gradient 


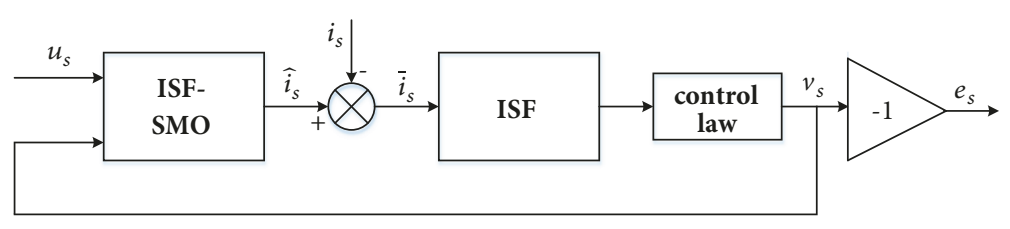

FIgURE 3: Schematic diagram of ISF-SMO.

descent method close to the target value. According to the principle of gradient descent method, the recursive formula of parameter vector can be expressed as

$$
\theta_{k+1}=\theta_{k}-\mu \nabla F(e(k)),
$$

where $\mu$ represents the search step in gradient direction and the value of $\mu$ determines the convergence rate of parameter vector. The gradient of variance function in (32) is

$$
\nabla F(e(k))=\nabla E\left(e^{2}(k)\right)=-E(e(k) x(k)) .
$$

By substituting (38) with (37), we can get

$$
\theta_{k+1}=\theta_{k}+\mu E(e(k) x(k)) .
$$

Equation (39) is a recursive formula to find the optimal solution by using gradient descent method. In practical applications, $E(e(k) x(k))$ is an unknown quantity and is difficult to be calculated by measurement, so it is usually replaced by the mean value of $L$ sampling points, that is,

$$
\widehat{E}(e(k) x(k))=\frac{1}{L} \sum_{l=0}^{L-1}[e(k-l) x(k-l)] .
$$
as

For ease of calculation, set $L=1$, then (39) can be expressed

$$
\theta_{k+1}=\theta_{k}+\mu e(k) x(k) .
$$

Equation (41) is Least Mean Square (LMS) algorithm. And the convergence direction of (41) is the same as that of (37). The key to implement LMS algorithm is to determine $\mu$. When $0<\mu<2 / \operatorname{tr}(R)$, LMS algorithm is convergent, but $R$ is unknown. For this reason, an approximate method is needed to determine the upper and lower limits of $\mu$. For stationary stochastic processes:

$$
\operatorname{tr}(R)=L E\left[x^{2}(k)\right],
$$

where $L$ is the dimension of input vector, then the range of $\mu$ can be determined as

$$
0<\mu<\frac{2}{L E\left(x^{2}(k)\right)},
$$

where $E\left(x^{2}(k)\right)=(1 / L) \sum_{l=0}^{L-1} x^{2}(k-l)$. Then (43) can be transformed as

$$
0<\mu<\frac{2}{x^{T}(k) x(k)}
$$

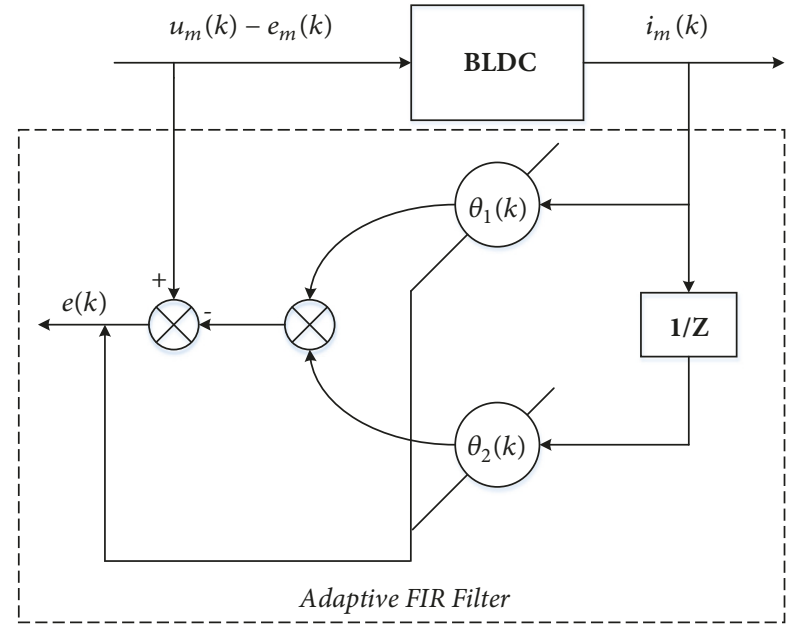

FIGURE 4: Schematic diagram of adaptive FIR filter.

Introduce normalized coefficient $\beta(0<\beta<2)$ and take $\mu(k)=\beta / x^{T}(k) x(k)=\beta /\|x(k)\|$ to replace the fixed coefficient $(\mu)$, then the normalized LMS recursive algorithm is

$$
\theta_{k+1}=\theta_{k}+\frac{\beta}{\|x(k)\|} e(k) x(k) .
$$

Compared with standard LMS algorithm, the normalized LMS algorithm has a variable correction gain $(\mu(k))$, that is, the variable step size LMS algorithm.

As shown in (28), the resistance $(R)$ is related to line's current; however, the inductor $(L)$ is related to the differential of line's current. The value of the line's current can be measured directly in actual application, but its derivative cannot. That is to say, the identification results of resistance value $(R)$ with NLMS are more accurate. In this paper, only resistance values $(R)$ are identified, and the simulation results show that the variation of inductor value $(L)$ has little effect on the identification results of the line's back-EMF.

\section{Simulation Results and Discussions}

The system diagram of sensorless control of BLDC with cascade feedback observer identification method is shown in Figure 2. The model is built based on Matlab/Simulink. PID controller is applied for speed controller and current controller in this paper. The details of ISF-SMO and adaptive FIR filter are shown in Figures 3 and 4, respectively. Table 1 gives the main parameters of BLDC and control system. 


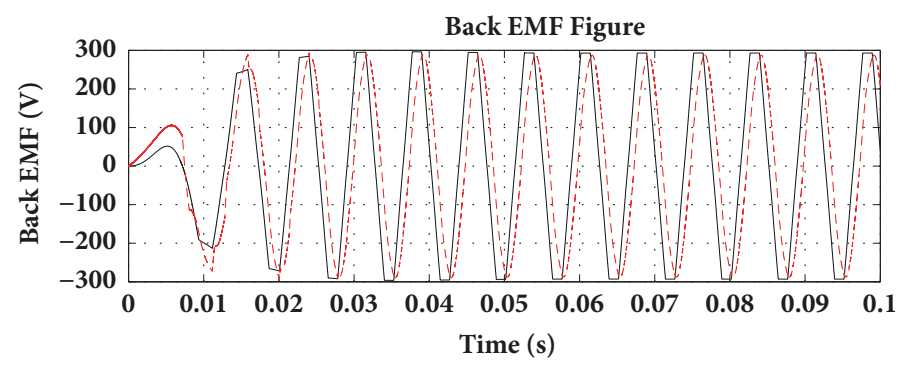

Figure 5: Identification result of conventional SMO.

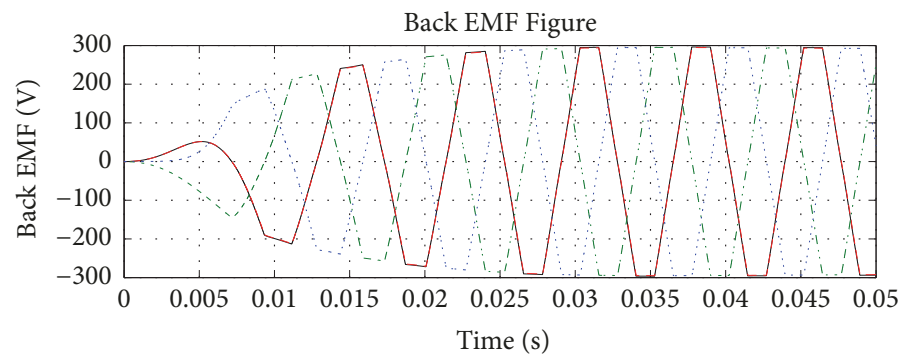

FIGURE 6: Identification result of ISF-SMO.

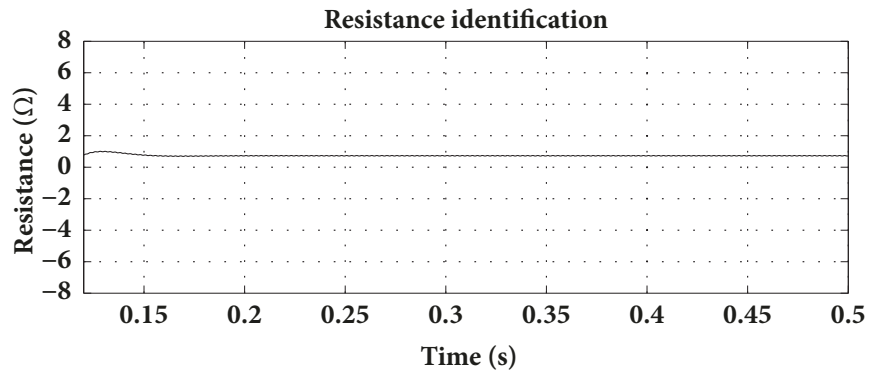

Figure 7: Identification result of resistance value $\left(R_{S}\right)$.

TABLE 1: Main parameters of simulation system.

\begin{tabular}{lc}
\hline Parameter & Value \\
\hline$R s$ & $0.356 \Omega$ \\
$L$ & $0.0083 \mathrm{H}$ \\
$\psi_{f}$ & $0.175 \mathrm{~Wb}$ \\
$J$ & $0.0008 \mathrm{Kgm}^{2}$ \\
$P_{n}$ & 6 \\
$c$ & 30 \\
$f$ & 0.5 \\
$k$ & -100 \\
$\lambda_{0}$ & 20 \\
$\lambda_{1}$ & 8 \\
\hline
\end{tabular}

3.1. Simulation Results of the Conventional SMO and ISF$S M O$. Both of the conventional first-order SMO and STASMO based sensorless control systems are constructed under continuous-time domain and the system bandwidth is the same. Simulation results of the conventional firstorder SMO and ISF-SMO are shown in Figures 5 and 6, respectively. Comparing these, the chattering problem is eliminated, but the result without phase lag of ISF-SMO is much better than the result with phase lag of conventional first-order SMO.

3.2. Simulation Results of Cascade Feedback Observer and ISF-SMO. In practical engineering, the resistance value will increase with the increase of temperature. In order to compare simulation result more clearly, we change the resistance value from $0.356 \Omega$ to $0.712 \Omega$. In this case, the motor motion is speed step (from 0 to $1000 \mathrm{rpm}$ ). The identification result of resistance $\left(R_{S}\right)$ is shown is Figure 7 . Simulation results are shown in Figure 8. In Figures 8(a), 8(c), 8(e), and 8(g), it is obvious that there is a large error when the resistance value changes with ISF-SMO control, especially at the time of acceleration stage, speed change stage, and load disturbance stage. In the real world, the problem will be exaggerated by discretization and measurement noises. Larger estimation error and even instability may occur. Therefore, online estimating of the resistance value is necessary in terms of estimation accuracy and system stability. 


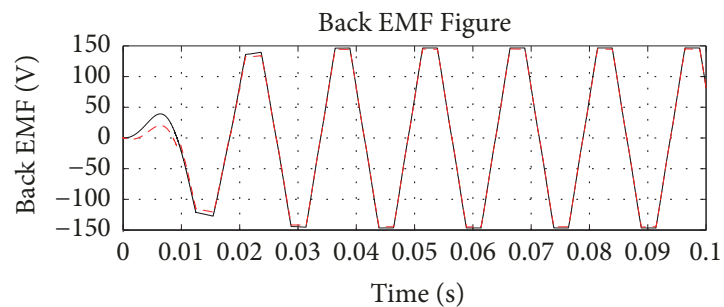

(a) Identification result of ISF-SMO when speed is $1000 \mathrm{rpm}$.

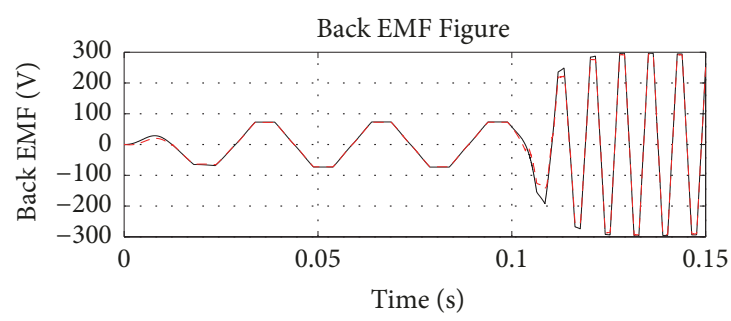

(c) Identification result of ISF-SMO when speed is from $500 \mathrm{rpm}$ to $2000 \mathrm{rpm}$.

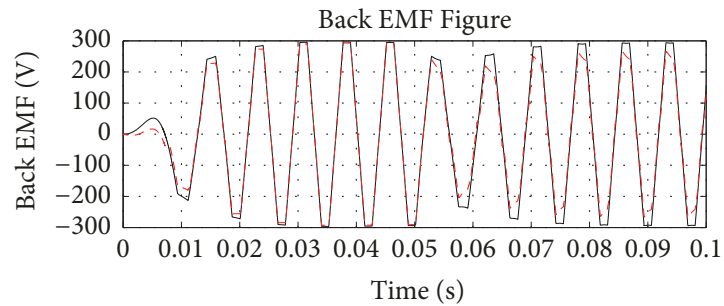

(e) Identification result of ISF-SMO when speed is $1000 \mathrm{rpm}$ with load $10 \mathrm{Nm}$ at $0.05 \mathrm{~s}$.

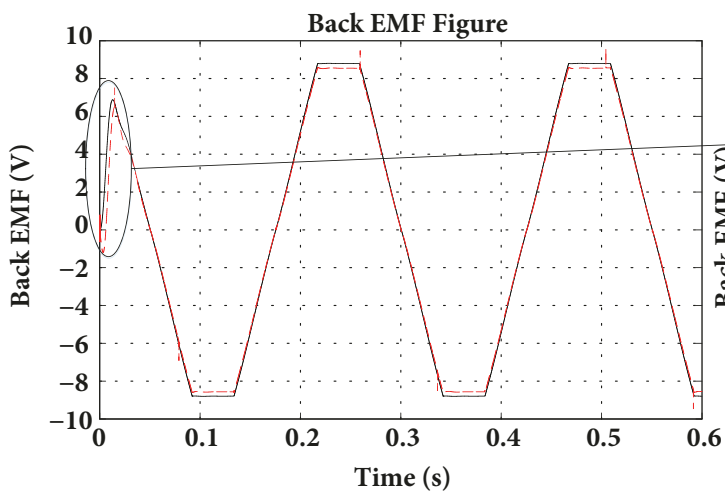

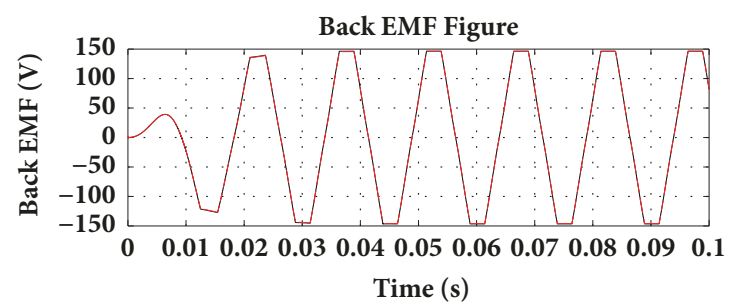

(b) Identification result of cascade feedback observer when speed is $1000 \mathrm{rpm}$.

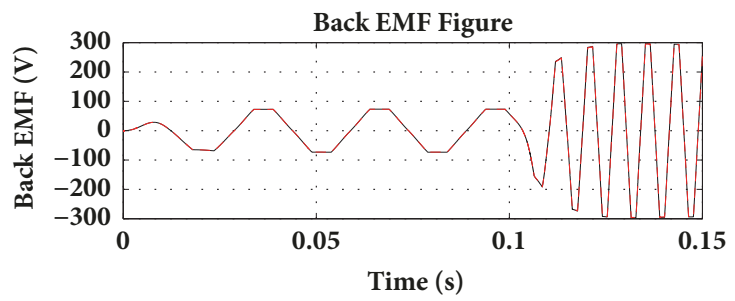

(d) Identification result of cascade feedback observer when speed is from $500 \mathrm{rpm}$ to $2000 \mathrm{rpm}$.

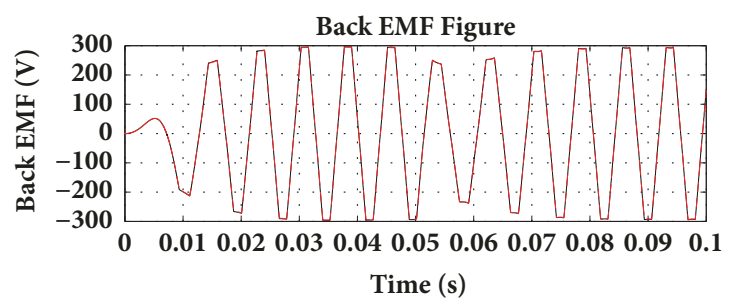

(f) Identification result of cascade feedback observer when speed is $1000 \mathrm{rpm}$ with load $10 \mathrm{Nm}$ at $0.05 \mathrm{~s}$.

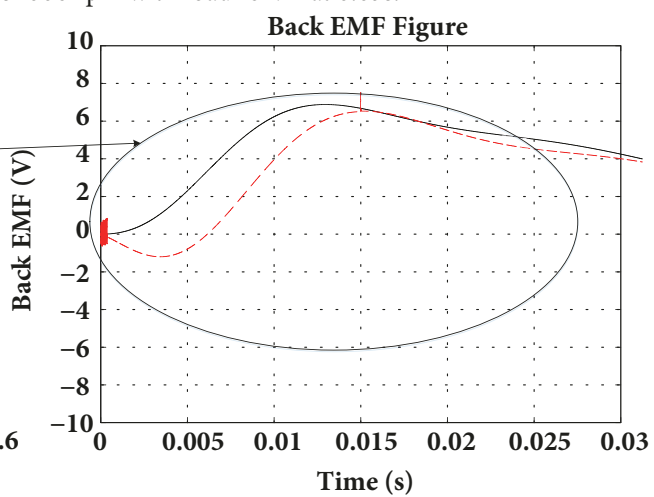

(g) Identification result of ISF-SMO when speed is $60 \mathrm{rpm}$.
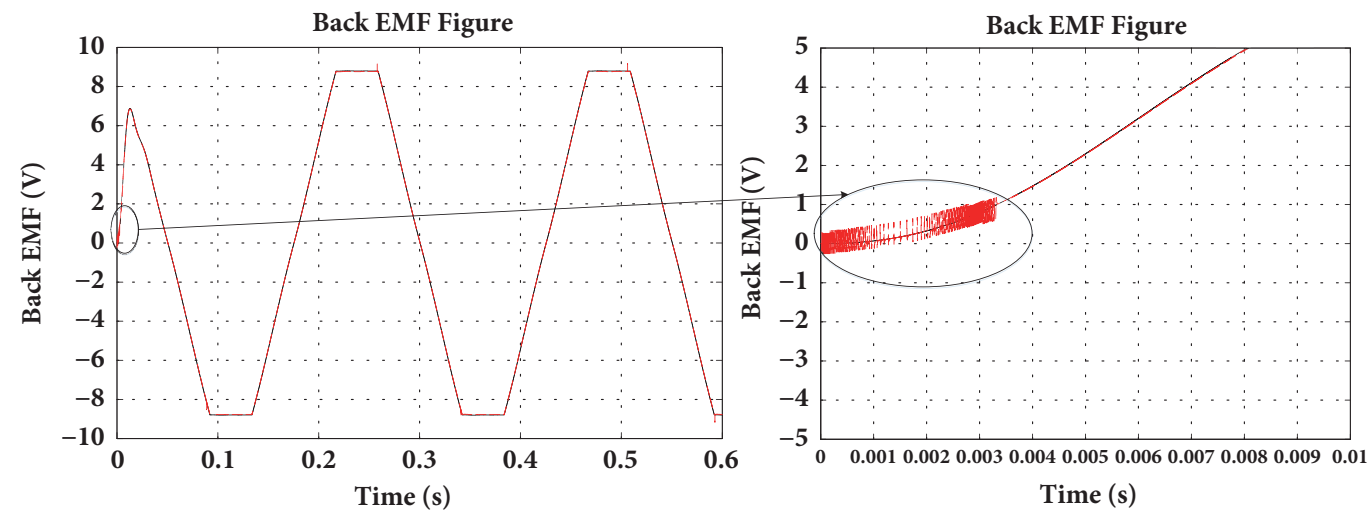

(h) Identification result of cascade feedback observer when speed is $60 \mathrm{rpm}$.

Figure 8: Compare simulation results of cascade feedback observer and ISF-SMO. (a), (c), (e), and (h) are the results of ISF-SMO, and (b), (d), (f), and (g) are the results of cascade feedback observer. 


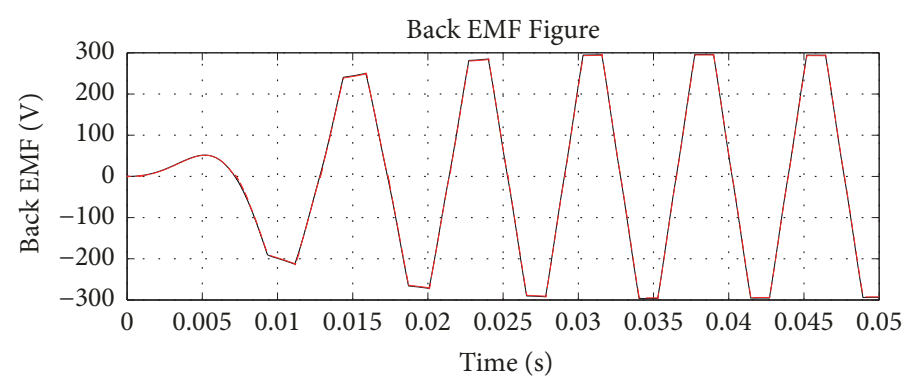

(a) Identification result of ISF-SMO when speed is $2000 \mathrm{rpm}$ with inductance value of $0.0166 \mathrm{H}$.

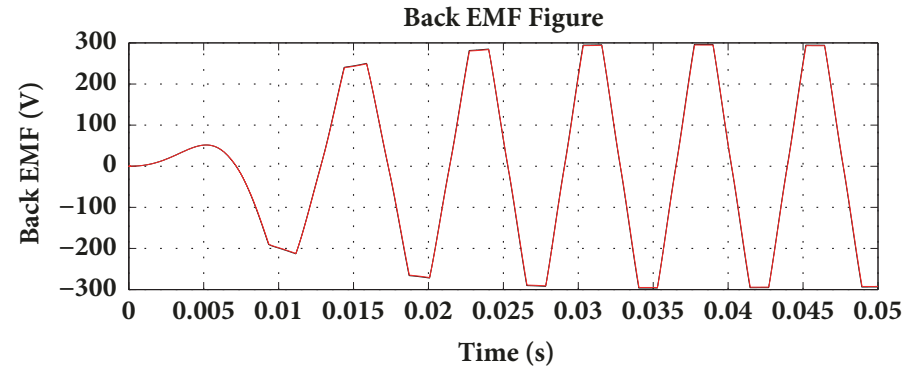

(b) Identification result of ISF-SMO when speed is $2000 \mathrm{rpm}$ with inductance value of $0.0083 \mathrm{H}$.

FIGURE 9: Compare simulation results of ISF-SMO with inductance value of $0.0166 \mathrm{H}$ and ISF-SMO with inductance value of $0.0083 \mathrm{H}$. (a) is the result of ISF-SMO with inductance value of $0.0166 \mathrm{H}$, and $(\mathrm{b})$ is the result of ISF-SMO with inductance value of $0.0083 \mathrm{H}$.

The simulation results of the cascade feedback observer identification method are shown in Figure 8. The system configuration is the same as that without the resistance value change. From Figures 8(b), 8(d), 8(f), and 8(h), it is obvious that the identification results are coinciding with reference EMF basically, even at the time of speed change stage and load disturbance stage. But at the acceleration stage of ultralow speed, there is some chattering.

From the discussion above, it can be concluded that the resistance variation has a great influence on estimation accuracy and robustness of the ISF-SMO. The effectiveness of online estimation of resistance value has been validated by simulations.

The influence of inductance variation on the ISF-SMO sensorless control system is also investigated. The simulation model is controlled by ISF-SMO based sensorless control method with the inductance value of $0.0166 \mathrm{H}$ (Figure 9(a)) and the inductance value of $0.0083 \mathrm{H}$ (Figure 9(b)), respectively. The simulation results are shown in Figure 9. It can be seen that inductance variation has little influence on estimation error, as shown in Figure 9. Because $L_{S}\left(d i_{s} / d t\right)$ is small at steady state, so the influence of inductance variation can be neglected.

\section{Experiment Results and Discussion}

Before the structure design and processing completion of extremity exoskeleton, the effectiveness of sensorless control for joint drive unit of extremity exoskeleton with cascade feedback observer is verified on a semiphysical simulation test bench. The control system test bench is shown in
Figure 10. The control system mainly includes controller, motor control card, current sensor, voltage sensor, drive units, and BLDC.

In experimental results, the Hall signal identified by cascade feedback observer is output by DO. The phase voltage, phase current, actual Hall signal, and Hall signal identified by feedback observer can be measured by oscilloscope. The experimental results are shown in Figures 11-14. The oscilloscope interface contains phase voltage (cyan), phase current (pink), actual Hall signal (yellow), and Hall signal identified by cascade feedback observer (green). Figures 11-14 are the identification results at $2000 \mathrm{rpm}, 4000 \mathrm{rpm}, 5000$ $\mathrm{rpm}$, and $6000 \mathrm{rpm}$, respectively.

By comparing the actual Hall signal with Hall signal identified by cascade feedback observer, it can be found that their rising edge and descending edge are basically the same; that is, the correct commutation information which is used for BLDC commutation can be obtained by cascade feedback observer. The performance of proposed sensorless control method is verified by the experimental results.

\section{Conclusion}

In this paper, the cascade feedback observer based on ISFSMO and adaptive FIR filter is proposed, which will be used for sensorless control for joint drive unit of lower extremity exoskeleton. The chattering problem in conventional SMO is alleviated by designing an Integral-Switch-Function sliding mode surface based on the improved Integral-SwitchFunction Sliding-Mode-Control. In the meantime, an online resistance value $\left(R_{S}\right)$ estimation method based on adaptive 


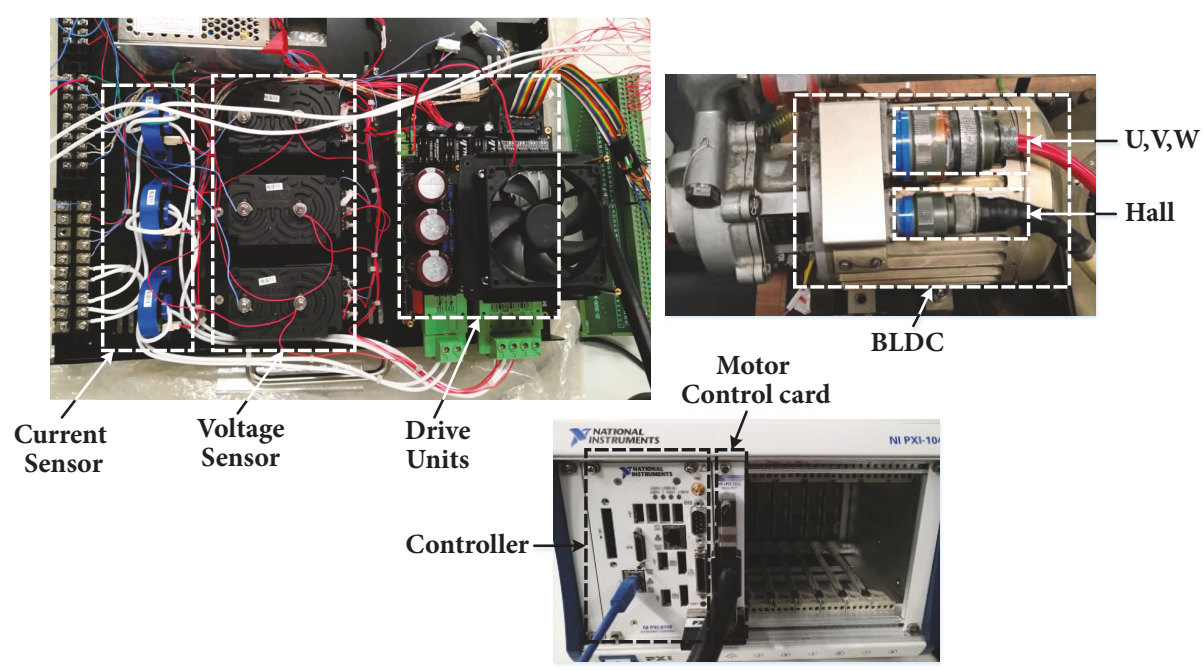

FIgURE 10: The control system test bench.

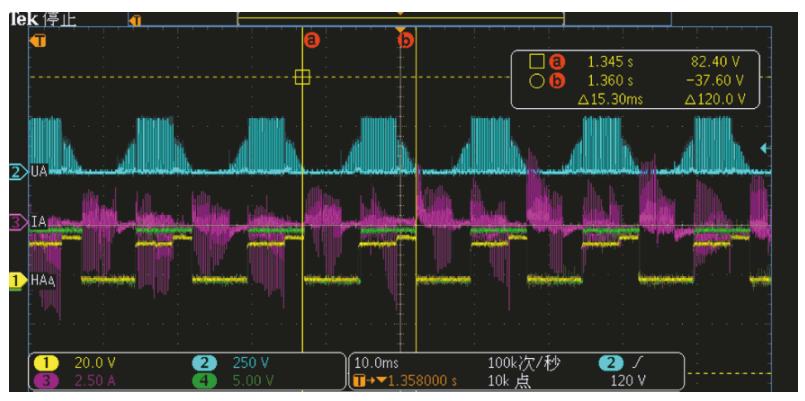

FIGURE 11: Experimental result of cascade feedback observer when speed is $2000 \mathrm{rpm}$.

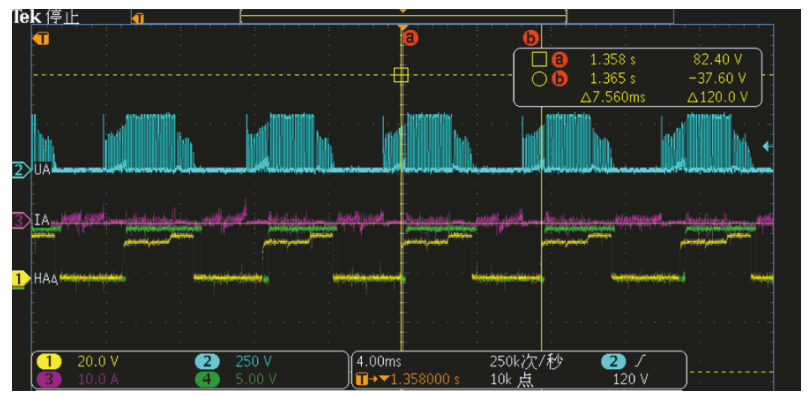

FIGURE 12: Experimental result of cascade feedback observer when speed is $4000 \mathrm{rpm}$.

FIR filter is utilized to obtain the accurate resistance value $\left(R_{S}\right)$, which improves the identification precision of backEMF significantly, especially at the time of acceleration stage, speed change stage, and load disturbance stage. Simulations and experiments are carried out to verify its validation. The results show that the proposed cascade feedback observer can improve the stability and robustness of system. However, because the proposed cascade feedback observer is based on machine model, it is scarcely capable of operating at the

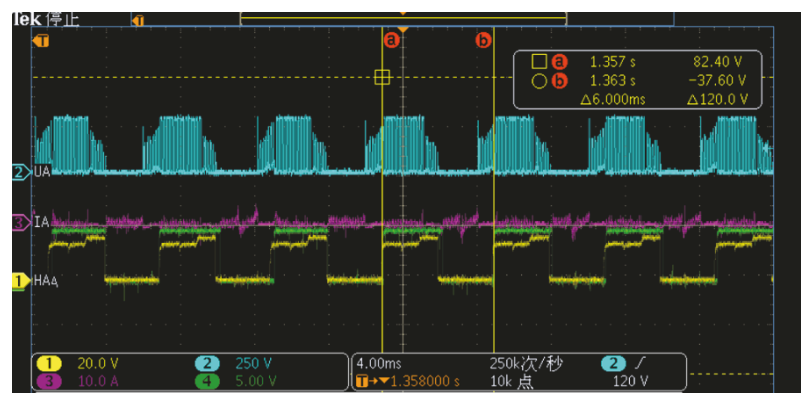

FIGURE 13: Experimental result of cascade feedback observer when speed is $5000 \mathrm{rpm}$.

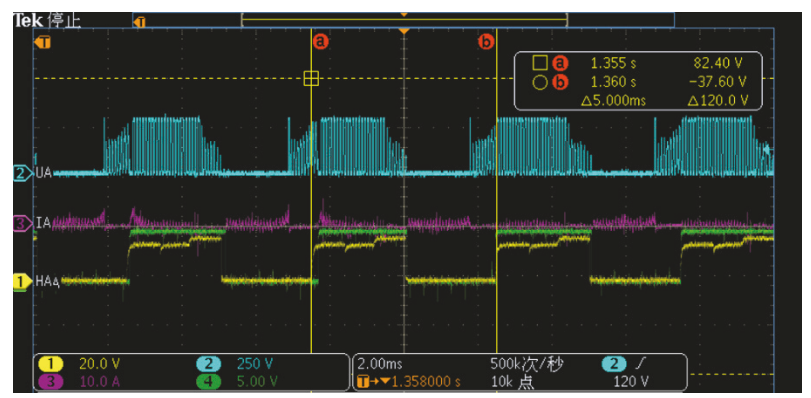

FIGURE 14: Experimental result of cascade feedback observer when speed is $6000 \mathrm{rpm}$.

ultralow speed. In the future work, we will take a transitional scheme to solve this problem, such as high frequency injection method.

\section{Data Availability}

The simulation model data and simulation result data used to support the findings of this study are available from the corresponding author upon request. 


\section{Conflicts of Interest}

The authors declare that there are no conflicts of interest regarding the publication of this paper.

\section{Acknowledgments}

This work was supported by the Chinese National Science Foundation (no. 51075017). The authors would like to thank the anonymous reviewers for their valuable comments.

\section{References}

[1] R. Manikandan and R. Arulmozhiyal, "Intelligent position control of a vertical rotating single arm robot using BLDC servo drive," Journal of Power Electronics, vol. 16, no. 1, pp. 205-216, 2016.

[2] Y. Sankai, "Leading edge of cybernics: robot suit HAL," in Proceedings of the SICE-ICASE International Joint Conference, pp. P-1-P-2, Busan, South Korea, October 2006.

[3] B. Michaud, Y. Cherni, M. Begon, G. Girardin-Vignola, and P. Roussel, "A serious game for gait rehabilitation with the Lokomat," in Proceedings of the 2017 International Conference on Virtual Rehabilitation, ICVR 2017, Canada, June 2017.

[4] E. Prassler and A. Baroncelli, "Team ReWalk Ranked First in the Cybathlon 2016 Exoskeleton Final [Industrial Activities]," IEEE Robotics and Automation Magazine, vol. 24, no. 4, pp. 8-10, 2017.

[5] G. Wang, L. Yang, G. Zhang, X. Zhang, and D. Xu, "Comparative Investigation of Pseudorandom High-Frequency Signal Injection Schemes for Sensorless IPMSM Drives," IEEE Transactions on Power Electronics, vol. 32, no. 3, pp. 2123-2132, 2017.

[6] D. Kim, Y.-C. Kwon, S.-K. Sul, J.-H. Kim, and R.-S. Yu, "Suppression of injection voltage disturbance for high-frequency squarewave injection sensorless drive with regulation of induced high-frequency current ripple," IEEE Transactions on Industry Applications, vol. 52, no. 1, pp. 302-312, 2016.

[7] S. S. Alex and A. E. Daniel, "An Efficient Position Tracking Smoothing Algorithm for Sensorless Operation of Brushless DC Motor Drives," Modelling and Simulation in Engineering, vol. 2018, Article ID 4523416, 9 pages, 2018.

[8] P. Mercorelli, "A Two-Stage Sliding-Mode High-Gain Observer to Reduce Uncertainties and Disturbances Effects for Sensorless Control in Automotive Applications," IEEE Transactions on Industrial Electronics, vol. 62, no. 9, pp. 5929-5940, 2015.

[9] Y. Shi, K. Sun, L. Huang, and Y. Li, "Online identification of permanent magnet flux based on extended Kalman filter for IPMSM drive with position sensorless control," IEEE Transactions on Industrial Electronics, vol. 59, no. 11, pp. 4169-4178, 2012.

[10] P. Mercorelli, "A two-stage augmented extended Kalman filter as an observer for sensorless valve control in camless internal combustion engines," IEEE Transactions on Industrial Electronics, vol. 59, no. 11, pp. 4236-4247, 2012.

[11] T. Bernardes, V. F. Montagner, H. A. Grundling, and H. Pinheiro, "Discrete-time sliding mode observer for sensorless vector control of permanent magnet synchronous machine," IEEE Transactions on Industrial Electronics, vol. 61, no. 4, pp. 1679-1691, 2014.

[12] Hong-Ru Li, Zhi-Bin Jiang, and Nan Kang, "Sliding Mode Disturbance Observer-Based Fractional Second-Order Nonsingular Terminal Sliding Mode Control for PMSM Position
Regulation System," Mathematical Problems in Engineering, vol. 2015, Article ID 370904, 14 pages, 2015.

[13] P. Mercorelli, "A Motion-Sensorless Control for Intake Valves in Combustion Engines," IEEE Transactions on Industrial Electronics, vol. 64, no. 4, pp. 3402-3412, 2017.

[14] O. Saadaoui, A. Khlaief, A. Chaari, and M. Boussak, "A new approach rotor speed estimation for PMSM based on sliding mode observer," in Proceedings of the 15th International Conference on Sciences and Techniques of Automatic Control and Computer Engineering, STA 2014, pp. 968-973, Tunisia, December 2014.

[15] W. Hu and Y. Geng, "Model-free adaptive control of BLDCM based on improved sliding mode observer," Journal of Electronic Measurement and Instrumentation, vol. 30, no. 3, 2016.

[16] L. Qi, T. Jia, and H. Shi, "A novel sliding mode observer for PMSM sensorless vector control," in Proceedings of the 2011 IEEE International Conference on Mechatronics and Automation, ICMA 2011, pp. 1646-1650, China, August 2011.

[17] D. Liang, J. Li, R. Qu, and W. Kong, "Adaptive SecondOrder Sliding-Mode Observer for PMSM Sensorless Control Considering VSI Nonlinearity," IEEE Transactions on Power Electronics, 2017.

[18] X. Wang, T. Fu, and X. Wang, "Position sensorless control of BLDC motors based on global fast terminal sliding mode observer," Journal of Power Electronics, vol. 15, no. 6, pp. 15591566, 2015.

[19] P. Mercorelli, "Parameters identification in a permanent magnet three-phase synchronous motor of a city-bus for an intelligent drive assistant," International Journal of Modelling, Identification and Control, vol. 21, no. 4, pp. 352-361, 2014.

[20] D. C. Huynh and M. W. Dunnigan, "Advanced particle swarm optimisation algorithms for parameter estimation of a singlephase induction machine," International Journal of Modelling, Identification and Control, vol. 15, no. 4, pp. 227-240, 2012.

[21] M. Jain, M. Singh, A. Chandra, and S. S. Williamson, "Sensorless control of permanent magnet synchronous motor using ANFIS based MRAS," in Proceedings of the 2011 IEEE International Electric Machines and Drives Conference, IEMDC 2011, pp. 599606, Canada, May 2011.

[22] L. Zhao, J. Huang, H. Liu, B. Li, and W. Kong, "Second-order sliding-mode observer with online parameter identification for sensorless induction motor drives," IEEE Transactions on Industrial Electronics, vol. 61, no. 10, pp. 5280-5289, 2014.

[23] K. Liu, Z. Q. Zhu, and D. A. Stone, "Parameter estimation for condition monitoring of PMSM stator winding and rotor permanent magnets," IEEE Transactions on Industrial Electronics, vol. 60, no. 12, pp. 5902-5913, 2013.

[24] D. Liang, J. Li, and R. Qu, "Sensorless Control of Permanent Magnet Synchronous Machine Based on Second-Order SlidingMode Observer With Online Resistance Estimation," IEEE Transactions on Industry Applications, vol. 53, no. 4, pp. 36723682, 2017.

[25] A. Levant, "Sliding order and sliding accuracy in sliding mode control," International Journal of Control, vol. 58, no. 6, pp. 12471263, 1993.

[26] A. Levant, "Robust exact differentiation via sliding mode technique," Automatica, vol. 34, no. 3, pp. 379-384, 1998.

[27] T. Nagasaka and K. Kobayashi, "Wiener-Hopf analysis of the diffraction by a thin material strip," in Proceedings of the 2016 URSI International Symposium on Electromagnetic Theory, EMTS 2016, pp. 557-560, Finland, August 2016. 


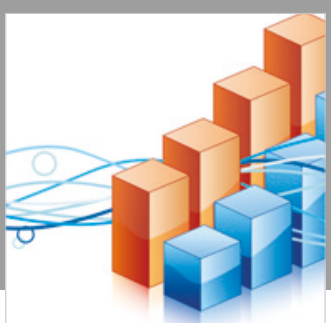

Advances in

Operations Research

\section{-n-m}
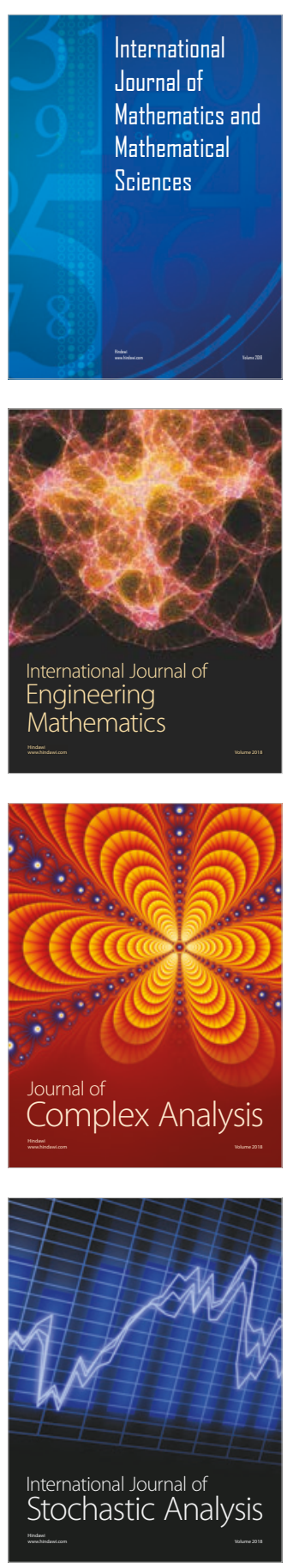
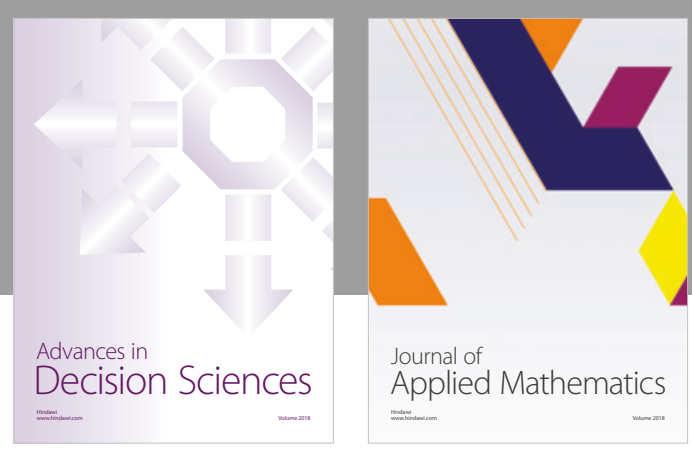

Journal of

Applied Mathematics
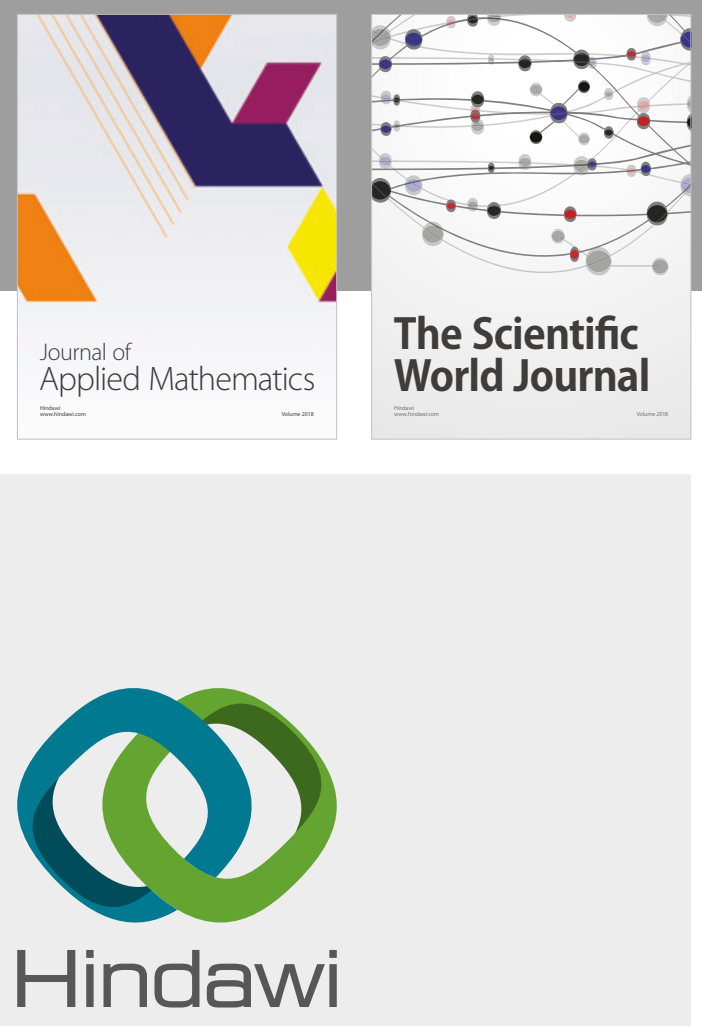

Submit your manuscripts at

www.hindawi.com

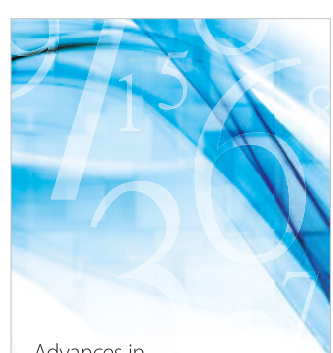

Advances in
Numerical Analysis
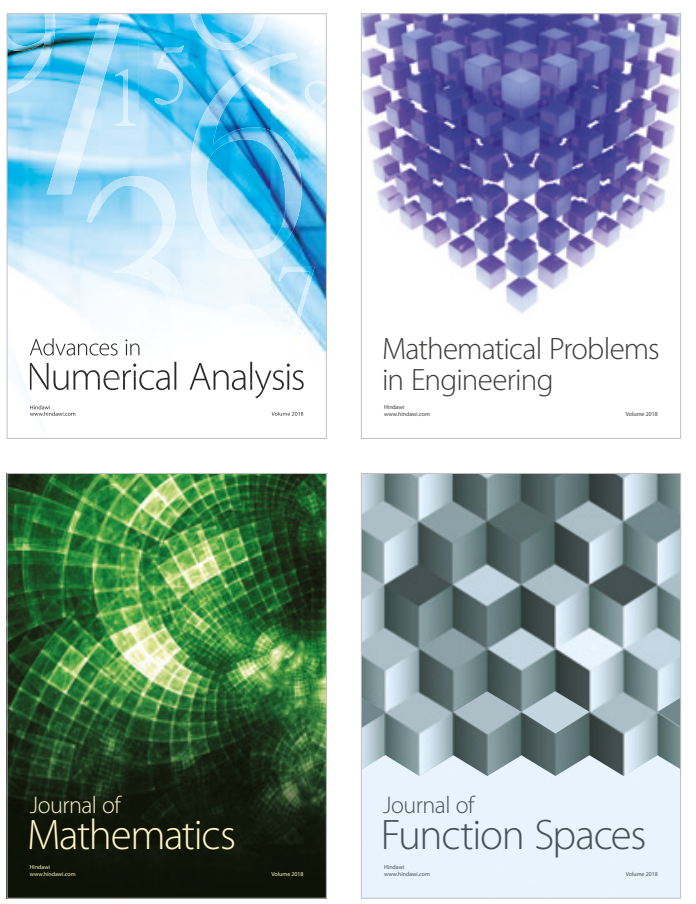

Mathematical Problems in Engineering

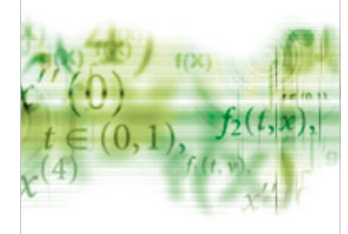

International Journal of

Differential Equations

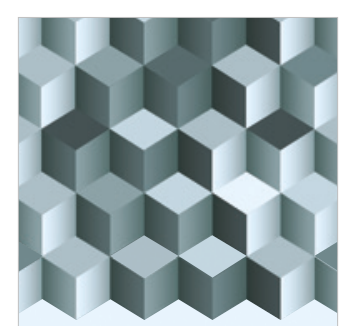

Journal of

Function Spaces

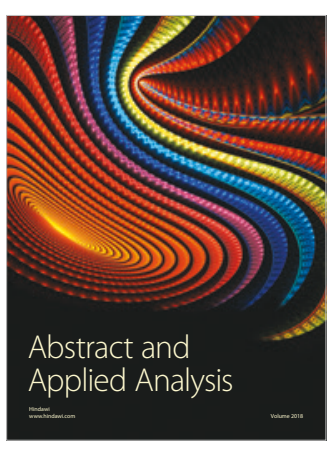

The Scientific

World Journal

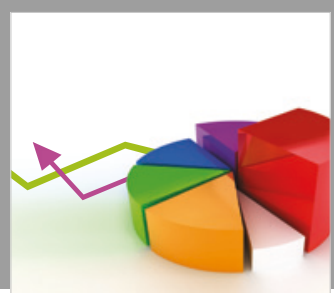

Journal of

Probability and Statistics
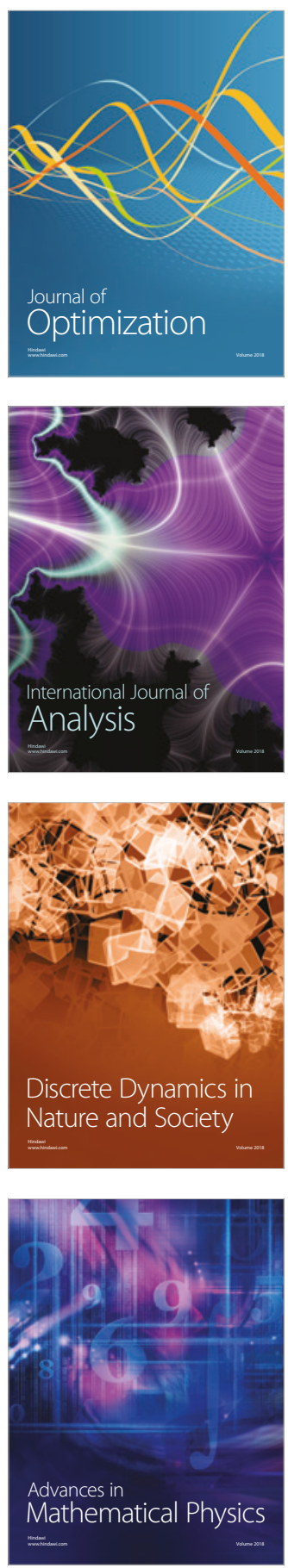